Article

\title{
Correcting the Error in Measuring Radiation Received by a Person: Introducing Cylindrical Radiometers
}

\author{
Robert D. Brown (D) \\ Landscape Architecture and Urban Planning, Texas A\&M University, College Station, TX 77843, USA; \\ Robert.brown@tamu.edu; Tel.: +1-979-458-3192
}

Received: 11 October 2019; Accepted: 18 November 2019; Published: 21 November 2019

\begin{abstract}
Most human energy budget models consider a person to be approximately cylindrical in shape when estimating or measuring the amount of radiation that they receive in a given environment. Yet, the most commonly used instrument for measuring the amount of radiation received by a person is the globe thermometer. The spherical shape of this instrument was designed to be used indoors where radiation is received approximately equally from all directions. But in outdoor environments, radiation can be strongly directional, making the sphere an inappropriate shape. The international standard for measuring radiation received by a person, the Integral Radiation Measurement (IRM) method, yields a measure of the Mean Radiant Temperature (Tmrt). This method uses radiometers oriented in the four cardinal directions, plus up and down. However, this setup essentially estimates the amount of energy received by a square peg, not a cylinder. This paper identifies the errors introduced by both the sphere and the peg, and introduces a set of two new instrument that can be used to directly measure the amount of radiation received by a vertical cylinder in outdoor environments. The Cylindrical Pyranometer measures the amount of solar radiation received by a vertical cylinder, and the Cylindrical Pyrgeometer measures the amount of terrestrial radiation received. While the globe thermometer is still valid for use in indoor environments, these two new instruments should become the standard for measuring radiation received by people in outdoor environments.
\end{abstract}

Keywords: energy budget modeling; human thermal comfort; heat health; biometeorology; micrometeorology; microclimatology

\section{Introduction}

Global Climate Change (GCC) and Urban Heat Island Intensification (UHII) combined produce urban environments that are often hotter than the surrounding countryside. This can have negative effects on both chronic and acute health of urban residents. People are less likely to walk in overheated environments [1,2] and the US Surgeon General [3] has identified lack of walking as a key to chronic health problems. There is also an increase in morbidity and mortality during heat waves [4] and this increase can be linked to the physical characteristics of urban environments. Areas with higher amounts of tree canopies and less hard surfaces like asphalt and concrete have lower levels of acute health issues during heat waves [5]. In order to design urban environments that are safer during heat waves and more thermally comfortable at all times, urban planners and designers need valid and reliable evidence on which to base their designs. This has led to an increased interest in modeling and measuring the energy budgets of people in outdoor environments [6,7].

There are many models of outdoor thermal comfort and they have taken several different approaches. Johansson et al. [6] has called for a standardization in instruments and methods, while Coccolo et al. [7] conducted a comprehensive review and identified considerable variation in modeling approaches. Despite the different methods and approaches, there is almost universal agreement that, at the microclimate scale during hot weather, solar and terrestrial radiation have a substantial effect 
on the human energy budget. Models require accurate and precise estimates or measurements of radiation received; yet, the current instruments and models have built-in error.

Johansson et al. [6] identified several methods for determining the amount of radiation received by a person in an outdoor environment. This value is often reported as the mean radiant temperature (Tmrt), which is defined as the "uniform temperature of a surrounding surface giving off blackbody radiation, resulting in the same energy gain of a human body, given the prevailing radiation fluxes" [8] (p. 323) and is essentially the sum of all the solar and terrestrial radiation received by a person in a given environment. Brown and Gillespie [9] used a more easily-understood value of radiation absorbed by a person (Rabs), which is essentially the inverse of Tmrt.

Thorsson et al. [10] reported that Integral Radiation Measurement (IRM) is the most accurate method for determining Tmrt, but identified instrumental overestimates at high solar incidence angles and underestimates at low angles. This method involves measuring solar and terrestrial radiation simultaneously in six directions with directional weightings of 0.22 for each of north, south, east, west, and 0.06 for each of up and down directions [11]. This essentially measures the radiation received by an extruded square "peg" (Figure 1).
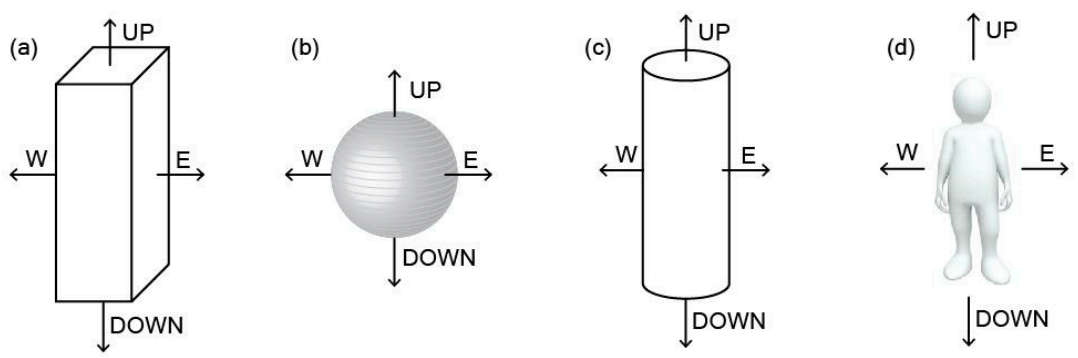

Figure 1. The shape of the three instruments/methods for measuring radiation received by a person in a landscape. (a) The Integral Radiation Measurement (IRM) as described by Thorsson et al. [10] measures radiation in each of the four cardinal directions, plus upward and downward. This essentially describes an extruded 'peg'. (b) The globe thermometer is spherical and absorbs radiation equally from all directions. A thermometer inside the globe provides an average temperature that is translated into a Mean Radiant Temperature (Tmrt) value through an equation. (c) The cylindrical radiation thermometer [9] measures the amount of radiation absorbed by a vertical cylinder but relies on an empirical equation to estimate the amount of convective cooling. (d) The shape of a typical person is more similar to a cylinder than to a peg or a sphere.

Johansson et al. [6] identified the globe thermometer as another method of estimating Tmrt but said that it tends to overestimate Tmrt during shady conditions and underestimates it in sunny weather. This instrument is spherical in shape, which does not look very much like a typical human body (Figure 1).

Humans arguably are neither square pegs nor spherical globes, but are more typically cylindrical in shape (Figure 1) and they have been commonly modeled as such $[9,12]$.

These three different shapes of instruments in the same environment will yield different values of solar and terrestrial radiation received. The Cylindrical Radiation Thermometer (CRT) has a shape that most closely resembles a typical human, but it relies on an empirical heat flux equation [9] that can lead to errors in low or high wind situations.

The goal of this paper was therefore twofold: (1) To compare, through the use of three-dimensional geometrical analysis, the radiation received by square pegs, spheres, and cylinders in outdoor environments; and (2) to identify a more accurate and precise method of measuring the radiation received by people in outdoor environments. 


\section{Materials and Methods}

The three instrument shapes (square peg, globe, and cylinder) were assessed in terms of their geometry and how their shape influences the measurement of solar and terrestrial radiation. For these tests, the up and down directions will not be included. Similarly, diffused and reflected radiation will not be included. The goal was not to provide a complete assessment of the radiant environment, but rather to illustrate situations that cause errors. Each instrument was placed first in a theoretical horizontal flat plane with no objects to obstruct or reflect the solar radiation, and secondly with a sun-warmed wall to (i) the north of the instrument; and (ii) to the north-east of the instrument. The wall was heated by incident solar radiation during the day and emitted terrestrial radiation. The amount of solar and terrestrial radiation received by each shape at test times of the day and with the wall in test locations are calculated and the results from the different shaped instruments are compared.

\section{Results}

\subsection{Geometric Assessment of Solar Beam Radiation at Different Solar Angles}

\subsubsection{Square Peg (IRM)}

Low Sun Angle: When the sun rises exactly in the east and provides $400 \mathrm{Wm}^{-2}$ of beam radiation on a vertical flat plate, the IRM pyranometer facing directly toward the east will record $400 \mathrm{Wm}^{-2}$, while the other three instruments-facing south, west, and north-will all record $0 \mathrm{Wm}^{-2}$ beam radiation. The average amount of beam radiation received by the four vertical faces is $100 \mathrm{Wm}^{-2}$ (Figure 2a).

If the sun rises instead in the southeast with the same $400 \mathrm{Wm}^{-2}$ beam radiation, the beam will hit both the east-facing and south-facing radiometers at $45^{\circ}$, so each one will measure $400 \times \cos 45^{\circ}=$ $283 \mathrm{Wm}^{-2}$. The other two radiometers measure $0 \mathrm{Wm}^{-2}$ beam, so the average of the four radiometers is $141 \mathrm{Wm}^{-2}$ beam (Figure 2a).

The orientation of the instruments resulted in a $41 \%$ difference in measurement from the same amount of solar radiation (Table 1).

Table 1. Direct beam solar radiation received by each of the instruments/methods at low and moderate sun angles. The Integral Radiation Measurement (IRM) value is dependent on the orientation of the instrument, while the globe thermometer yields values lower than the cylinder at low sun angles and higher than the cylinder at higher sun angles.

\begin{tabular}{|c|c|c|c|c|c|}
\hline $\begin{array}{c}\text { Solar } \\
\text { Elevation }\end{array}$ & Solar Azimuth & $\begin{array}{c}\text { Beam } \\
\left(\mathrm{Wm}^{-2}\right)\end{array}$ & $\begin{array}{c}\text { IRM } \\
\left(\mathrm{Wm}^{-2}\right)\end{array}$ & $\begin{array}{c}\text { Globe } \\
\left(\mathrm{Wm}^{-2}\right)\end{array}$ & $\begin{array}{c}\text { Cylinder } \\
\left(\mathrm{Wm}^{-2}\right)\end{array}$ \\
\hline $0^{\circ}$ & East $\left(90^{\circ}\right)$ & 400 & 100 & 100 & 128 \\
\hline $0^{\circ}$ & Southeast $\left(135^{\circ}\right)$ & 400 & 141 & 100 & 128 \\
\hline $45^{\circ}$ & $15^{\circ}$ East of South $\left(165^{\circ}\right)$ & 1000 & 216 & 250 & 226 \\
\hline $45^{\circ}$ & South $\left(180^{\circ}\right)$ & 1000 & 177 & 250 & 226 \\
\hline
\end{tabular}

High Sun Angle: When the sun is directly south of the instruments at solar noon, the south-facing instrument will receive radiation according to Lambert's Cosine Law [13]:

$$
\Phi=\Phi_{0} \cos \Theta
$$

where:

$\Phi=$ flux density at the surface $\left(\mathrm{Wm}^{-2}\right)$

$\Phi_{0}=$ flux density normal to the beam $\left(\mathrm{Wm}^{-2}\right)$

$\Theta=$ angle between beam and normal to the surface

In the case of a very clear day when the sun is providing $1000 \mathrm{Wm}^{-2}$ of beam radiation with an elevation angle of $45^{\circ}$ above the horizon, the south-facing instrument will receive $707 \mathrm{Wm}^{-2}$ of 
directional radiation, while the other three radiometers will receive 0 . The average amount received will be $177 \mathrm{Wm}^{-2}$.

If this same $1000 \mathrm{Wm}^{-2}$ was received when the sun was $15^{\circ}$ east of south, then the east-facing instrument will receive $707 \cos (90-15)=183 \mathrm{Wm}^{-2}$ while the south-facing instrument will receive $707 \cos (90-75)=682 \mathrm{Wm}^{-2}$. The west- and north-facing instruments will receive 0 . The average amount of beam radiation measured will be $216 \mathrm{Wm}^{-2}$. This is a $22 \%$ difference from the same amount of radiation received directly from the south (Table 1).

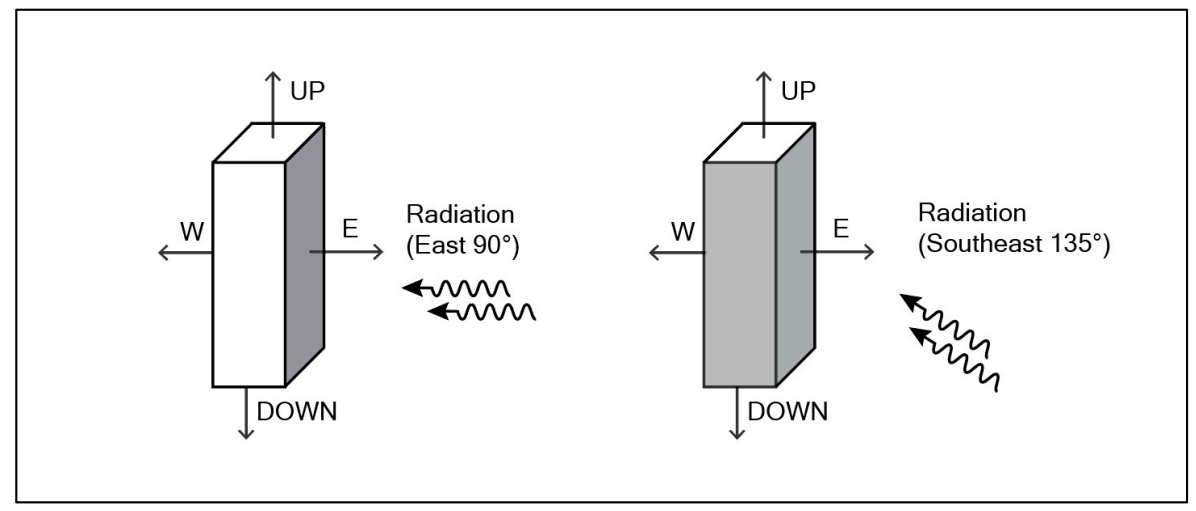

(a)

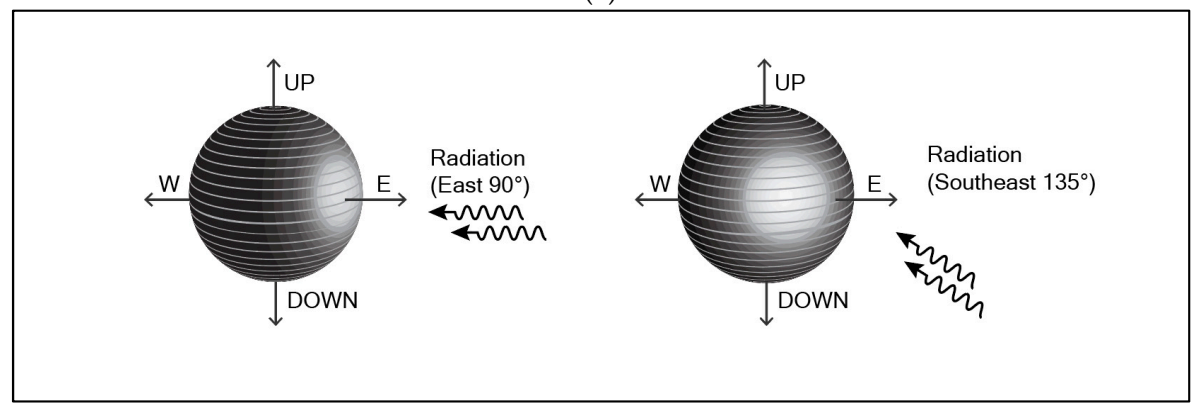

(b)

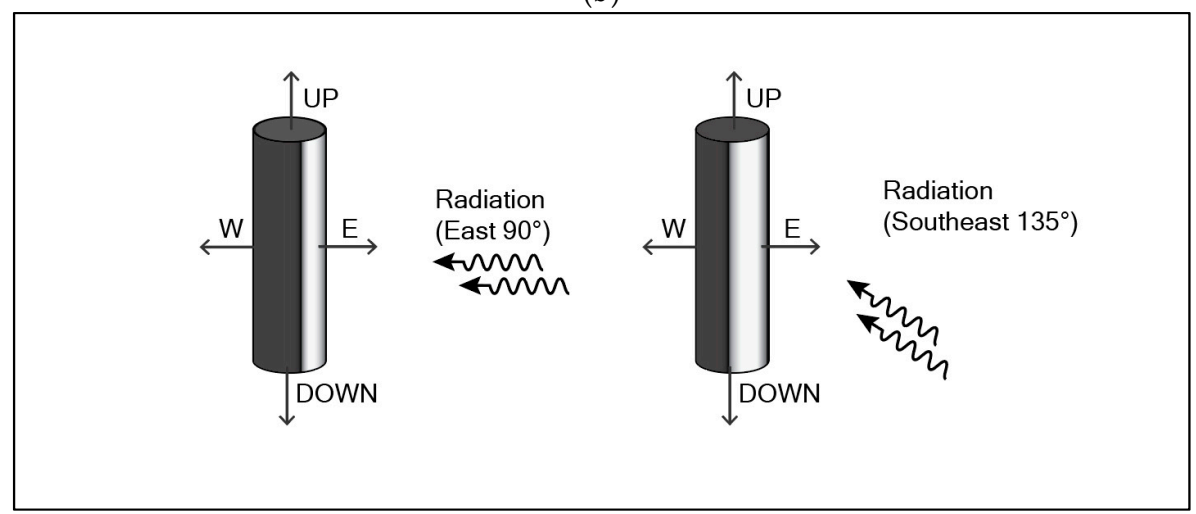

(c)

Figure 2. A theoretical environment where each of the instruments is located on a horizontal flat plane with nothing to obstruct the solar radiation beam. (a) The IRM method yields different values depending on the orientation of the instrument. (b) The globe thermometer yields overestimate at high sun angles and underestimates at low sun angles. (c) The cylindrical radiation thermometer provides a result that is the most similar to what a person would receive.

\subsubsection{Spherical Globe Thermometer}

Low Sun Angle: Whether the sun rises in the east or southeast will have no effect on the beam radiation received by the spherical globe thermometer. The $400 \mathrm{Wm}^{-2}$ is distributed over the surface 
of the sphere. The surface area of the sphere is four times the cross-sectional area, so the instrument will measure $100 \mathrm{Wm}^{-2}$ (Figure 2b).

High Sun Angle: Similarly, when the sun is high in the sky to the south, the ratio will remain the same. The amount of solar radiation received by a circular flat plate is divided by 4 to yield the average amount received by the sphere. Thus, when the sun provides beam radiation of $1000 \mathrm{Wm}^{-2}$, the average receipt of the sphere is $250 \mathrm{Wm}^{-2}$.

\subsubsection{Vertical Cylinder}

Low Sun Angle: When the sun rises in the east and provides $400 \mathrm{Wm}^{-2}$ of beam radiation on a vertical flat plate, the direct beam hitting a cylinder is absorbed according to the cross-sectional area, which is simply diameter $\times$ length. It will be spread over the surface area of the cylinder, which is diameter $\times$ length $\times$ pi, so the capture area $=1 / \mathrm{pi}=0.32$. Thus, it will receive $400 \times 0.32=128 \mathrm{Wm}^{-2}$ no matter where the sun rises (Figure 2c).

High Sun Angle: Whether the sun is in the south or $15^{\circ}$ east of south, the cylinder will receive the $1000 \mathrm{Wm}^{-2}$ of radiation according to the cosine law, so it will receive $707 \mathrm{Wm}^{-2}$. This amount will be spread over the surface area of the cylinder, so it receives $707 \times 0.32=226 \mathrm{Wm}^{-2}$ whether the sun is in the south or $15^{\circ}$ east of south.

\subsection{Geometric Assessment of Terrestrial Radiation}

This assessment considers two situations: (a) A wall to the north of the instruments, and (b) a wall to the north-east of the instruments. The two walls are considered to be the same temperature as heated up by absorbed solar radiation and are the same distance from the instruments. The location of the wall will have a similar impact on the amount of terrestrial radiation received by a person in that location in a landscape and the orientation of the instrument or the wall does not influence the result.

For this test example, the ground is considered to be covered with grass and is at $25^{\circ} \mathrm{C}$; the wall fills $50 \%$ of the sky hemisphere and is $50{ }^{\circ} \mathrm{C}$, while clear sky fills the other $50 \%$ of the sky hemisphere. For illustration purposes, the emissivity of surfaces is assumed to be 1.0 for all cases.

\subsubsection{Square Peg (IRM)}

If the wall to the north of the instrument has a surface temperature of $50^{\circ} \mathrm{C}$, according to the Stefan-Boltzmann equation, it will be emitting $(273.15+50)^{4} \times 5.67 \times 10^{-8}=618 \mathrm{Wm}^{-2}$. The ground at $25^{\circ} \mathrm{C}$ will be emitting $448 \mathrm{Wm}^{-2}$ and the radiation from the sky can be estimated from Equation [12]:

$$
\text { Lsky }=213+5.5 \mathrm{Ta}
$$

In this case, the sky will emit $350.5 \mathrm{Wm}^{-2}$. The north-facing pyrgeometer will register $618 \mathrm{Wm}^{-2}$ while the south, east, and west facing pyrgeometers will record $0.5 \times 448+0.5 \times 350.5=399 \mathrm{Wm}^{-2}$. Averaging the four values yields $454.75 \mathrm{Wm}^{-2}$ (Figure 3a).

When the wall is to the northeast of the instrument, the north- and east-facing pyrgeometers will receive $50 \%$ from the ground, $25 \%$ from the sky, and $25 \%$ from the hot wall or $5 \times 448+25 \times 350.5+25$ $\times 618=466.1$. The south- and west-facing pyrgeometers will each receive $399 \mathrm{Wm}^{-2}$. The average value will be $432.6 \mathrm{Wm}^{-2}$.

\subsubsection{Spherical Globe Thermometer}

The bottom half of the globe will receive directional terrestrial radiation from the ground $=$ $448 \mathrm{Wm}^{-2}$. The upper half of the globe will receive $50 \%$ from the wall and $50 \%$ from the sky $=(0.5 \times$ $618)+(0.5 \times 350.5)=484.25 \mathrm{Wm}^{-2}$. The average of these two values is $466.1 \mathrm{Wm}^{-2}$. The location of the wall relative to the globe does not change this value (Figure $3 b$ ). 


\subsubsection{Vertical Cylinder}

Considering the sphere of influence on the cylinder, half of the terrestrial radiation will be received from the ground and half from the sky hemisphere. The ground portion will be $448 \mathrm{Wm}^{-2}$. The sky portion will be half from the sky and half from the wall $=(0.5 \times 350)+(0.5 \times 618)=484.25$. The average will be $466.1 \mathrm{Wm}^{-2}$ and as with the globe, the location of the wall relative to the cylinder does not change the amount of terrestrial radiation received (Figure 3c).
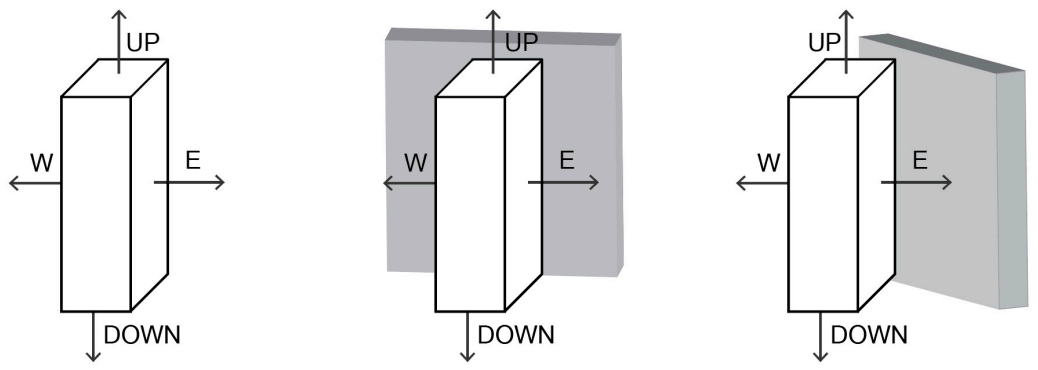

(a)
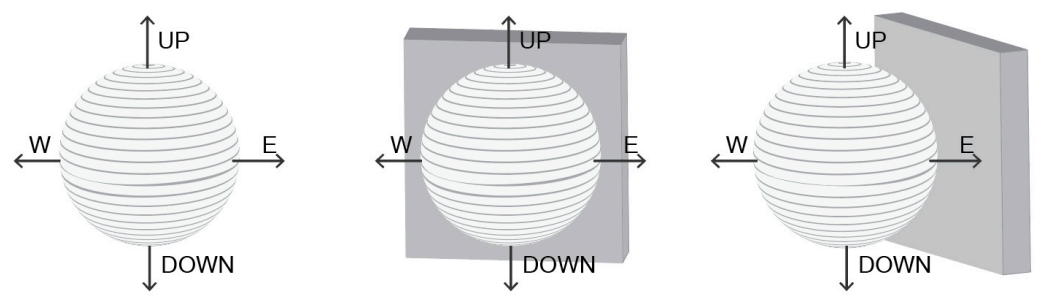

(b)
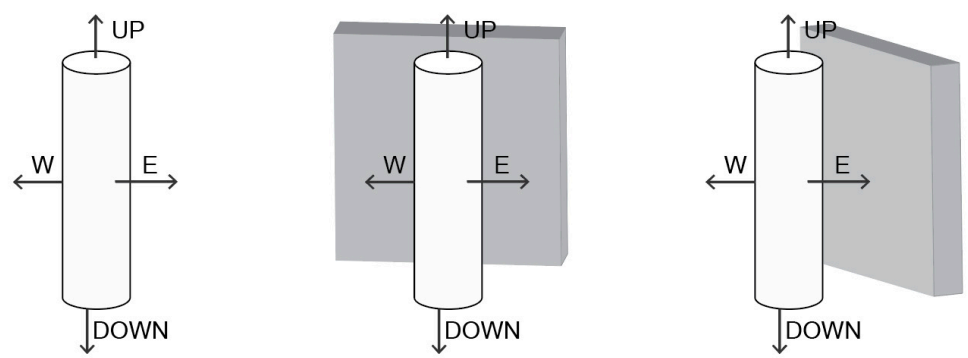

(c)

Figure 3. A theoretical environment where each of the instruments is set in an environment with a vertical wall to the north and the northeast. The vertical wall emits terrestrial radiation that is measured by each instrument. (a) The IRM underestimates the value in both cases; (b) the globe thermometer yields the correct value in all cases (which is why it is appropriate for use in indoor environments); and (c) the cylindrical radiation thermometer is not dependent on the orientation of the instrument and yields the same value at the globe thermometer. 
The different amounts of terrestrial radiation yielded by the three different shaped instruments is shown in Table 2.

Table 2. Terrestrial radiation received by each of the instruments when set beside a hot wall to the north and to the northeast. The IRM result is dependent on the orientation of the instrument, while the globe and cylindrical thermometers yield the same value.

\begin{tabular}{cccc}
\hline Location of Wall & IRM $\left(\mathbf{W m}^{-\mathbf{2}}\right)$ & Globe $\left(\mathbf{W m}^{-\mathbf{2}}\right)$ & Cylinder $\mathbf{( W m}^{-\mathbf{2}} \mathbf{)}$ \\
\hline North $\left(0^{\circ}\right)$ & 454.75 & 466.1 & 466.1 \\
Northeast $\left(45^{\circ}\right)$ & 432.6 & 466.1 & 466.1 \\
\hline
\end{tabular}

\section{Discussion}

As reported in the literature $[6,10]$ measurements taken by the IRM and the globe thermometer introduce small but important errors into the estimates of the amount of radiation a person receives in an outdoor environment. The geometric basis for these errors has been identified in this study. The cylindrical radiation thermometer, because of its shape, has the most appropriate geometry to represent a person, but it relies on an empirical convective heat loss equation to estimate the radiation received. What is needed is an instrument in the shape of the cylinder that does not require an empirical equation. This paper proposes new instrument designs that will correct the error and offer accurate and precise values of radiation received by a person in a landscape.

\section{Proposal for New Instruments to Directly Measure Solar and Terrestrial Radiation of a Cylinder}

This study proposes two new radiometers based on the same principles as the standard pyranometer and pyrgeometer; however, rather than measuring the radiation on a horizontal flat plate, they measure the amount of radiation received by a cylinder.

The Cylindrical Pyranometer (Figure 4) consists of a black cylinder with very low albedo encased in a slightly larger double glass cylinder. This allows solar radiation to pass through but will negate other effects, such as convective heat flux and terrestrial radiative flux. There is an array of fine wire thermocouples embedded just below the black skin mid-way up the cylinder and wired in series. The signal provides an average temperature of the cylinder, which, when compared with the control temperature, can be translated into incoming solar radiation in $\mathrm{Wm}^{-2}$.

(a)

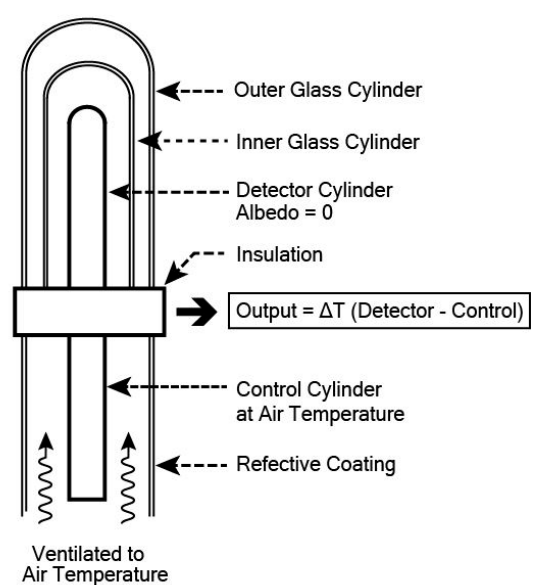

(b)

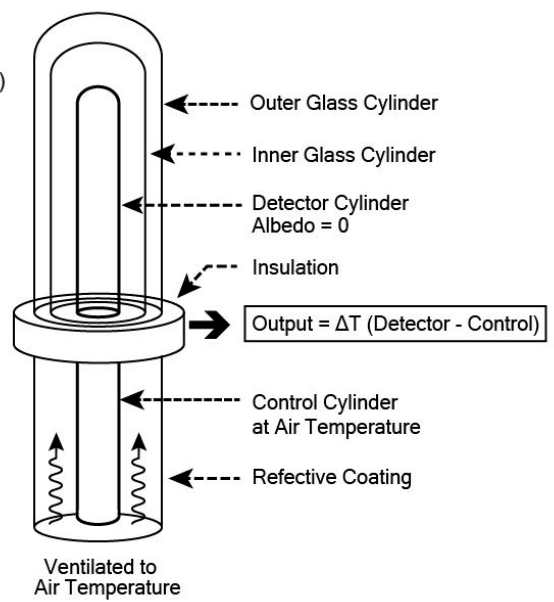

Figure 4. Design of a Cylindrical Pyranometer. (a) Cross-sectional view illustrates the relationship between the detector and the double glass shield; (b) Perspective view shows the cylindrical form of all components of the pyranometer. 
The Cylindrical Pyrgeometer (Figure 5) consists of a black cylinder with very low albedo and very low emissivity, but instead of glass, the enclosing cylinder is made of silicone with a thin film coating on the insider to block solar radiation. The signal provides an average temperature of the cylinder, which can readily be translated into $\mathrm{Wm}^{-2}$.

(a)

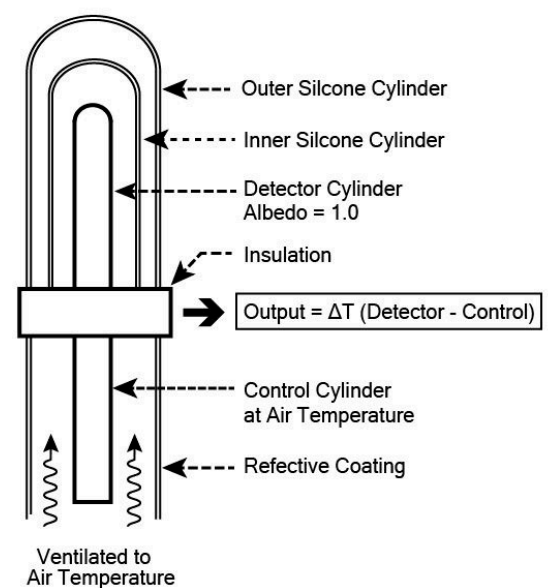

(b)

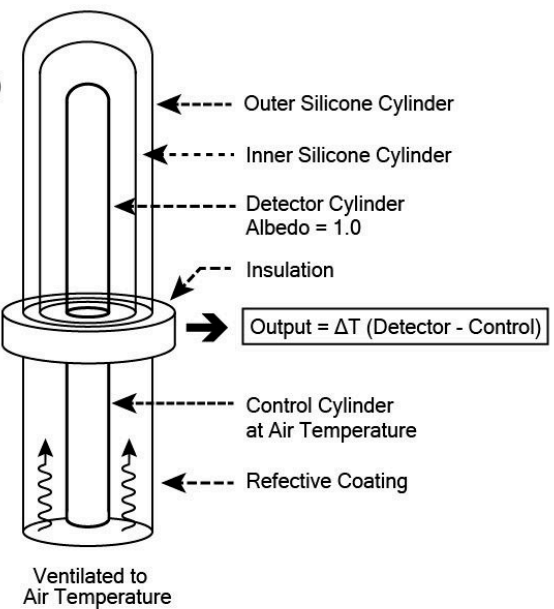

Figure 5. Design of a Cylindrical Pyrgeometer. (a) Cross-sectional view illustrates the relationship between the detector and the double silicon shield; (b) Perspective view shows the cylindrical form of all components of the pyrgeometer.

Instruments such as these radiometers will have a built-in uncertainty. It can be expected that these two instruments will have uncertainties similar to that of high-quality flat plate pyranometers and pyrgeometers, which are in the range of $3 \%$ to $5 \%$.

\section{Conclusions}

Instruments that are currently being used to measure and estimate radiation received by a person in outdoor environments yield incorrect results. Two new radiometers, a cylindrical pyranometer and a cylindrical pyrgeometer, will provide more accurate and precise measurements of the radiation a person receives in a landscape.

With more than $80 \%$ of the American population and more than $50 \%$ of people worldwide living in cities, it is critical that urban environments be designed to provide thermally comfortable environments for people. Radiation is a critical component of the energy budget of people in urban outdoor areas, particularly during extreme heat events, and it is important that design and planning decisions are made based on accurate and precise measurements.

\section{Patents}

The two instruments described in this study have been registered and are "patent pending".

Funding: The open access publishing fees for this article have been covered by the Texas A\&M University Open Access to Knowledge Fund (OAKFund), supported by the University Libraries and the Office of the Vice President for Research.

Acknowledgments: The diagrams in this paper were prepared by Kanghyun Lee. This paper was improved upon by the insightful suggestions of the reviewers.

Conflicts of Interest: The author declares no conflict of interest.

\section{References}

1. Lee, C.; Ory, M.G.; Yoon, J.; Forjuoh, S.N. Neighborhood walking among overweight and obese adults: Age variations in barriers and motivators. J. Community Health 2013, 38, 12-22. [CrossRef] [PubMed] 
2. Tucker, P.; Gilliland, J. The effect of season and weather on physical activity: A systematic review. Public Health 2007, 121, 909-922. [CrossRef] [PubMed]

3. US Surgeon General. Step it Up! The Surgeon General's Call to Action to Promote Walking and Walkable Communities; US Surgeon General: Washington, DC, USA, 2015.

4. Graham, D.A.; Vanos, J.K.; Kenny, N.A.; Brown, R.D. The relationship between neighbourhood tree canopy cover and heat-related ambulance calls during extreme heat events in Toronto, Canada. Urban For. Urban Green. 2016, 20, 180-186. [CrossRef]

5. Graham, D.A.; Vanos, J.K.; Kenny, N.A.; Brown, R.D. Modeling the effects of urban design on emergency medical response calls during extreme heat events in Toronto, Canada. Int. J. Environ. Res. Public Health 2017, 14, 778. [CrossRef] [PubMed]

6. Johansson, E.; Thorsson, S.; Emmanuel, R.; Krüger, E. Instruments and methods in outdoor thermal comfort studies-The need for standardization. Urban Clim. 2014, 10, 346-366. [CrossRef]

7. Coccolo, S.; Kämpf, J.; Scartezzini, J.L.; Pearlmutter, D. Outdoor human comfort and thermal stress: A comprehensive review on models and standards. Urban Clim. 2016, 18, 33-57. [CrossRef]

8. Matzarakis, A.; Rutz, F.; Mayer, H. Modelling radiation fluxes in simple and complex environments-Application of the RayMan model. Int. J. Biometeorol. 2007, 51, 323-334. [CrossRef] [PubMed]

9. Brown, R.D.; Gillespie, T.J. Estimating outdoor thermal comfort using a cylindrical radiation thermometer and an energy budget model. Int. J. Biometeorol. 1986, 30, 43-52. [CrossRef] [PubMed]

10. Thorsson, S.; Lindberg, F.; Eliasson, I.; Holmer, B. Different methods for estimating the mean radiant temperature in an outdoor urban setting. Int. J. Climatol. 2007, 27, 1983-1993. [CrossRef]

11. VDI. Environmental Meteorology, Interactions between Atmosphere and Surface; Calculation of Short-and Long Wave Radiation. Part I: Climate, VDI 3789, Part 2: VDI/DIN-Handbuch Reinhaltung der Luft, Band 1b; VDI: Düsseldorf, Germany, 1994.

12. Jendritzky, G.; de Dear, R.; Havenith, G. UTCI—Why another thermal index? Int. J. Biometeorol. 2012, 56, 421-428. [CrossRef] [PubMed]

13. Campbell, G. An Introduction to Environmental Biophysics; Springer: New York, NY, USA, 1977; 159p.

(C) 2019 by the author. Licensee MDPI, Basel, Switzerland. This article is an open access article distributed under the terms and conditions of the Creative Commons Attribution (CC BY) license (http://creativecommons.org/licenses/by/4.0/). 